\title{
Suited Occupant Injury Potential During Dynamic Spacecraft Flight Phases
}

Dub, M. O.

NASA

McFarland, S. M.

MEI Technologies

Copyright $@ 2010$ AIAA

\section{ABSTRACT}

In support of the Constellation Space Suit Element [CSSE], a new space-suit architecture will be created for support of Launch, Entry, Abort, Microgravity ExtraVehicular Activity [EVA], and post-landing crew operations, safety and, under emergency conditions, survival. The space suit is unique in comparison to previous launch, entry, and abort [LEA] suit architectures in that it utilizes rigid mobility elements in the scye (i.e., shoulder) and the upper arm regions. The suit architecture also utilizes rigid thigh disconnect elements to create a quick disconnect approximately located above the knee. This feature allows commonality of the lower portion of the suit (from the thigh disconnect down), making the lower legs common across two suit configurations. This suit must interface with the Orion vehicle seat subsystem, which includes seat components, lateral supports, and restraints. Due to the unique configuration of spacesuit mobility elements, combined with the need to provide occupant protection during dynamic vehicle events, risks have been identified with potential injury due to the suit characteristics described above.

To address the risk concerns, a test series has been developed in coordination with the Injury Biomechanics Research Laboratory [IBRL] to evaluate the likelihood and consequences of these potential issues. Testing includes use of Anthropomorphic Test Devices [ATDs; vernacularly referred to as "crash test dummies"], Post Mortem Human Subjects [PMHS], and representative seat/suit hardware in combination with high linear acceleration events. The ensuing treatment focuses on test purpose and objectives; test hardware, facility, and setup; and preliminary results.

\section{INTRODUCTION}

The Constellation Space Suit Element consists of two suit configurations: the Configuration 1 suit will be designed for Launch, Entry and Abort as well as contingency microgravity EVA; the Configuration 2 suit will be designed for Surface EVA operations. However, it is a primary design goal of the CSSE to provide as much modularity as possible between these two configurations - for example, the same gloves, boots and helmet may be used for both suit configurations. This architecture differs from the Shuttle program, which employs two very different suits with no common hardware - the Advanced Crew Escape Suit, or ACES is used for LEA, while the Extravehicular Mobility Unit [EMU] is used for microgravity EVA. Although there are large mass and volume drawbacks to this architecture, the advantage is having two different suit designs, each optimized for their own environments.

As such, the ACES is, with the exception of the neck ring, helmet and glove disconnect, an all-soft suit, which protects the crew during launch and reentry; meanwhile the EMU has many rigid elements which provide muchneeded pressurized mobility to the crewmember during an EVA. Although the ACES is a fully pressurizable suit, it is not designed to afford the wearer much in the way of mobility. Luckily, the mobility required of the crew during a scenario where the ACES would be pressurized is considerably small, and therefore not historically known to be a problem.

The Constellation Config 1 suit, however, must meet the occupant protection demands of an LEA suit, as well as the pressurized mobility demands of an EVA suit in the same design. In addition, the landing loads predicted by Constellation are considerably higher than those seen by Shuttle due to the fact that the Orion vehicle is designed for passive water landing under parachutes instead of an active runway landing like the Shuttle Orbiter. This is a significant engineering challenge.

To meet these various and other requirements, the current CSSE reference design for Configuration 1 (EVA System Reference [ESR] 2, shown in Figure 1) calls for a soft suit with specific rigid mobility elements in the scye and upper arm regions. In addition, this architecture also utilizes rigid thigh disconnects just above the knee, which provide a quick disconnect capability for the lower portion of the suit, which is common across both suit configurations. 
There are unknowns, however, associated with placing these rigid elements in a suit designed for protecting the crew during nominal and off-nominal LEA modes. A test series was developed in response to a NASA risk being tracked that spoke to these unknowns, particularly during the short period of time encompassed by landing, where loads could potentially be high enough to cause injury in an otherwise soft suit. Injuries that are most cause for concern are those that may inhibit crewmember egress from the vehicle in an emergency, such as bone fractures or nerve damage; however, any injury caused by the suit during a nominal landing is more or less considered unacceptable.

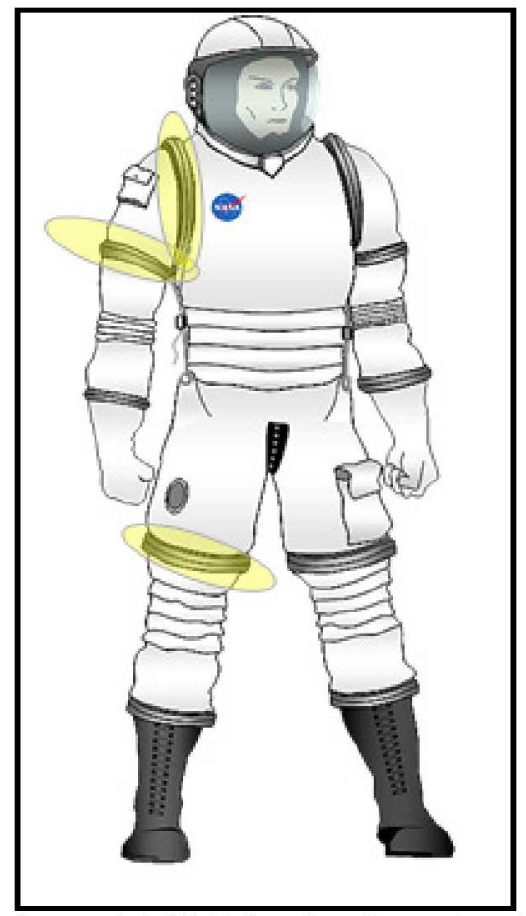

Figure 1: ESR2 for Configuration 1

The objective of this test series is to qualify the risk associated with these baselined suit architectural features (scye bearing, upper arm bearing, thigh disconnect).

\section{TESTING METHODOLOGY}

Although anthropomorphic test devices (ATDs) are commonly used in automotive injury potential testing (and many other areas) due to their repeatability, ease of use, high degree of instrumentation, and long-term cost, for this test post-mortem human subjects [PMHS] were selected as the primary testing mechanism. Although there would be information gained from using ATDs, it was determined that post-mortem human subjects would provide a much higher level of correlation to a live crewmember. At the same time, considering the uniqueness of the rigid elements being tested, there is no existing injury dataset against which to validate any ATD data (like there is in automotive crashes).
Post-mortem human subjects are commonly used today for a variety of purposes that provide great benefit to the living. For example, many PMHS are used to concentrate automotive crash testing to a specific area of the body (e.g., the head and neck, thoracic cage, etc). These tests can provide data on improving safety standards, increasing the fidelity of a virtual human injury model or ATD, or simply better understand the biomechanics of human injury. There is no question that PMHS benefit the science of injury biomechanics, and by extension, all of us.

A common concern when deciding between ATDs and PMHS is the issue of sample size. When testing with an ATD, an erroneous test can simply be redone, with little impact or marginal impact to cost and schedule. Furthermore, an ATD can be tested virtually an infinite number of times so as to provide a testing sample size deemed to be statistically significant. However, an erroneous test using a PMHS subject can easily become a cost and scheduling disaster, with lead times for subject procurement and instrumentation heading into weeks, if not months. Therefore, most test series employing PMHS typically have a small sample size when compared to an ATD test. For example, the regulations on air bags in the United States were defined using PMHS testing with a sample size of only XXX.

While it is cause for discussion it was found to not be a cause for concern. For one, it was determined that the benefits of using PMHS (particularly the increase in biofidelity) outweighed the drawbacks. Furthermore, human spaceflight has an inherently more conservative risk posture than the automotive world - only one or two injuries across 15 test points could be cause for a change to the suit architecture.

Subjects were selected for fit use for this test series by meeting certain criteria:

- Anthropometry - Males in the approximate $50^{\text {th }}$ percentile (stature; weight) were chosen for all data points

- Bone density - Bone Mineral Density (BMD) scans were performed prior to acceptance to preclude subjects who were osteopenic or had major bone deformities

- Other - Subjects were screened for blood-borne pathogens and other medical anomalies that may preclude them from PMHS testing

\section{TESTING FACILITIES}

In order to test the required landing loads, testing is being conducted at the Transportation Research Center [TRC] in East Liberty, OH. TRC has one of the only 24inch HYGE sled accelerators in the world (shown in Figure 2), capable of test accelerations up to 100Gs in magnitude. The Ohio State University [OSU] Injury Biomechanics Research Laboratory [IBRL] in nearby Columbus, $\mathrm{OH}$, with whom this test series is coordinated, 
provides the test subjects, medical and injury biomechanics expertise, subject instrumentation, pre and post-test imaging of the subjects, and finally, post-test autopsy and report.

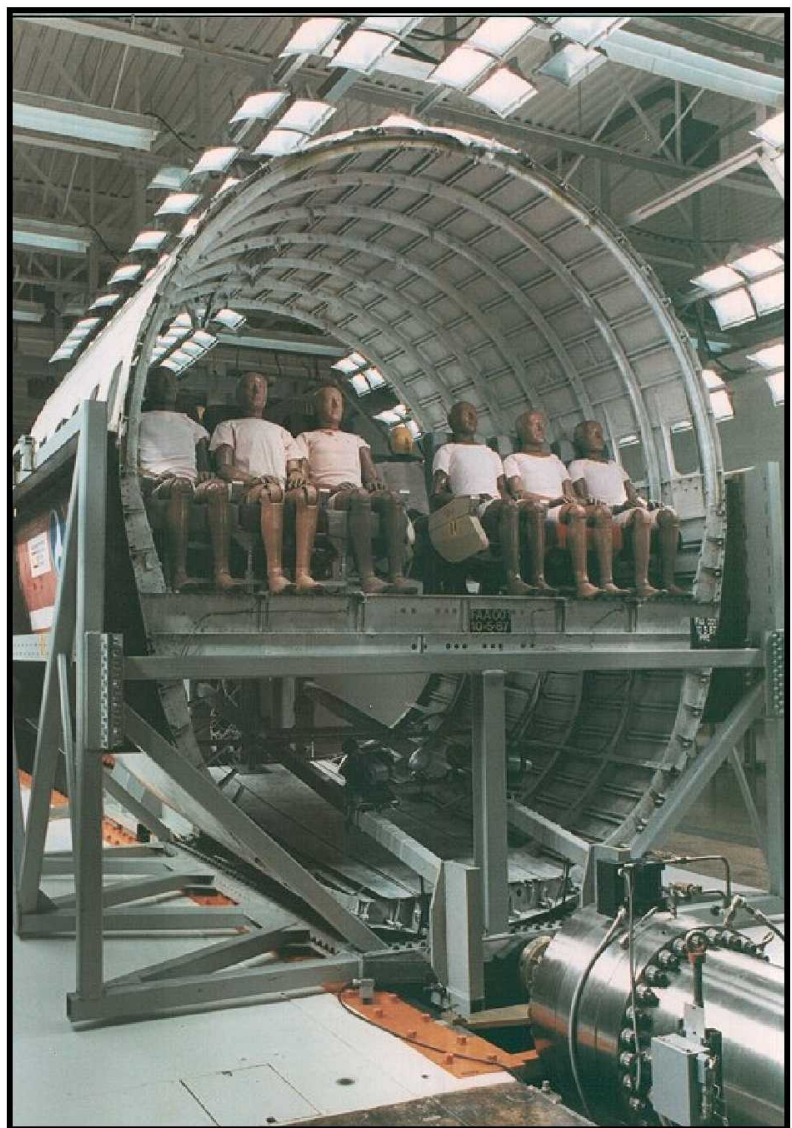

Figure 2: HYGE Crash Simulator (Actuator in lower right; Test Article at center)

\section{TEST VARIABLES AND CONTROLS}

The Constellation Program landing load data varies over time in response to changes in design and architecture, and is dependent on several variables such as crew weight, vehicle configuration, wind, sea states, crew position, etc. It was nevertheless necessary to choose one representative acceleration pulse to test against. Twenty-four off-nominal but "design-to" landing cases (12 high-wind launch aborts and 12 water landings with one parachute out) were considered as a target envelope.

These landing cases provided acceleration profiles at the Orion seat in the $X$ and $Z$ directions (as noted in Figure 3). No Y-direction or land landing (usually a result of a launch abort) cases were available at the time. By considering these 24 cases, a representative sled pulse of $11.5 \mathrm{Gs}$ was selected, which should correlate to a human dynamic response of $\sim 15 \mathrm{G}$. The total pulse duration was defined as $80 \mathrm{~ms}$. This $11.5 \mathrm{G} / 80 \mathrm{~ms}$ pulse was selected for all test directions:

- +X ("eyeballs in" - e.g., getting rear-ended)

- -X ("eyeballs out" - e.g., head-on collision)
- $\quad+$-Y ("eyeballs left/right" - e.g., side impact)

- $\quad+Z$ ("eyeballs down" - e.g. pushed into seat pan)

- - Z ("eyeballs up" - e.g., pulled out of seat pan)

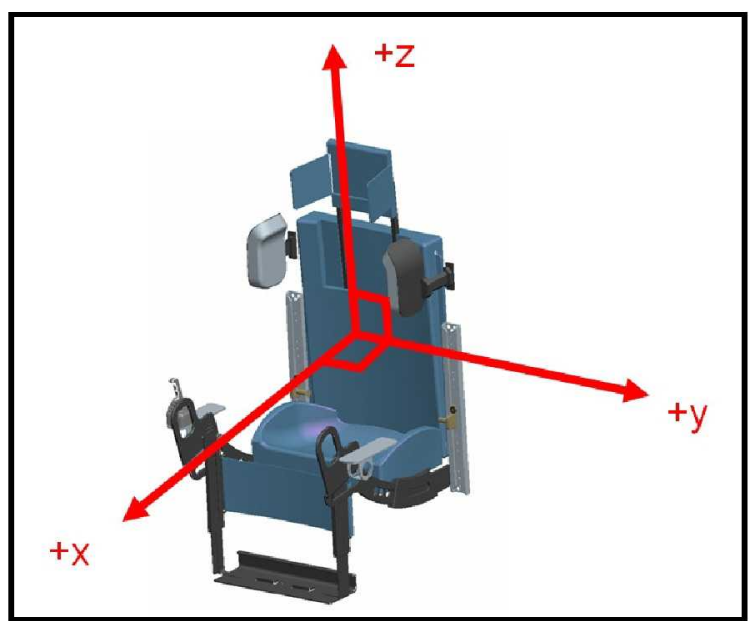

Figure 3: Landing Directions

Although it is expected that nominally, the $+X$ and $+Z$ landing loads will be higher than the others, one constant acceleration profile was selected for testing in all directions, both to model off-nominal scenarios (such as land landing roll-overs, loss of roll control, high sea states, etc) and to avoid the complexities associated with changing out the HYGE pins to facilitate different accelerations profiles on adjacent tests. A representative target acceleration profile is shown below in Figure 4.

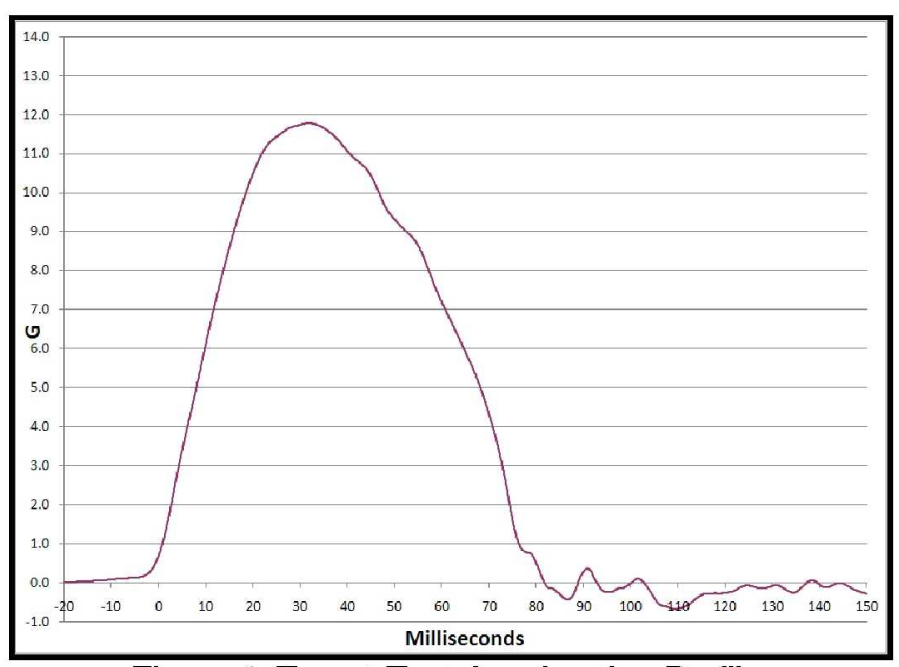

Figure 4: Target Test Acceleration Profile

In order to meet the test objectives, a test series with 12 subjects was selected. A test point matrix, shown in Table 1, was derived to provide at least two data points in each loading direction, and also provide data points for testing by the Vehicle Interface Element [VIE], which wanted to test vehicle umbilical connectors on different regions of the body to evaluate their injury potential. These data points will not be discussed in the context of this paper, but are denoted as "VIE" in the table. 
The table shows each data point, the test subject which is used to complete this data point, the testing direction and the primary area of injury focus. It should be noted that many test subjects are used for more than one data point. These assignments were carefully chosen to minimize the possibility that one test may affect or hide the results of another. In most or all cases, the plan is to perform imaging (CT, MRI and/or X-Ray) between each test and if an obvious injury has occurred, not to proceed with the second test point. As with many test programs, it may be necessary to change test point assignments or test directions based on previous results.

\begin{tabular}{|c|c|c|c|}
\hline $\begin{array}{l}\text { Test } \\
\text { Point }\end{array}$ & Subject & Direction & Area of Focus \\
\hline 1 & $A$ & $+\mathrm{X}$ & Posterior Shoulder \\
\hline 2 & B & $-X$ & Anterior Shoulder \\
\hline 3 & \multirow{2}{*}{ C } & $-Z$ & Superior Shoulder \\
\hline 4 & & $+Z$ & Thigh and Backbone \\
\hline 5 & $\mathrm{D}$ & $+\mathrm{X}$ & Posterior Shoulder \\
\hline 6 & $E$ & $-X$ & Anterior Shoulder \\
\hline 7 & \multirow{2}{*}{$\mathrm{F}$} & $+Y$ & Rib, Shoulder, etc. \\
\hline 8 & & $-Y$ & Rib, Shoulder, etc. \\
\hline 9 & \multirow{2}{*}{$\mathbf{G}$} & $-Z$ & Superior Shoulder \\
\hline 10 & & $+Z$ & Thigh and Backbone \\
\hline 11 & \multirow{2}{*}{$\mathrm{H}$} & $+\mathrm{X}$ & Posterior Shoulder \\
\hline 12 & & $+Z$ & VIE \\
\hline 13 & \multirow{2}{*}{ I } & $-X$ & Anterior Shoulder \\
\hline 14 & & $+X$ & VIE \\
\hline 15 & \multirow{2}{*}{$\mathrm{J}$} & $-Z$ & Superior Shoulder \\
\hline 16 & & $+Z$ & Thigh and Backbone \\
\hline 17 & \multirow{2}{*}{ K } & $+Y$ & Rib, Shoulder, etc. \\
\hline 18 & & $+X$ & VIE \\
\hline 19 & \multirow{2}{*}{$L$} & $+Z$ & VIE \\
\hline 20 & & $+\mathrm{X}$ & VIE \\
\hline
\end{tabular}

Table 1: Test Matrix

\section{TEST HARDWARE}

A substantial amount of new test hardware was required for this test. A new test seat was required to accommodate subject anthropometric variability and multiple test directions. A suit analog was required to simulate the rigid components of the suit but also allow for easy placement/removal of these components. Additional hardware was also required to fully support commencement of this test series.

\section{TEST SEAT FIXTURE}

A new test seat needed to be designed and constructed for this test series. Although previous NASA tests of this nature had used similar seats, the goal was to provide for a better range of anthropomorphic variability of the test subjects. Despite only accepting subjects in the $50^{\text {th }}$ percentile in stature and weight, it was discovered that other anthropometric measurements that drive seat design and fit (e.g. seated height, shoulder breadth, leg length, lower vs. upper leg length, etc) could be considerably far from the $50^{\text {th }}$ percentile, and therefore, it was often difficult or impossible to get subjects into a static seat without permanent and time-consuming modifications.

Therefore, a new seat design was needed to accommodate variability in these critical measurements. The seat was designed to provide several primary functions:

- Withstand specified testing loads

- Provide marginal adjustment for anthropometry of a $\sim 50^{\text {th }}$ percentile male

- Provide means to reconfigure the seat for the 6 different test directions

- Accommodate test instrumentation as required

- Provide representative conformal features at the shoulder, hip and knee as required

- Accommodate a 5-point harness for subject restraint

- Accommodate on-board video cameras

- Interface with the existing HYGE carriage (red arrow in Figure 5), which is the typical platform onto which test articles, in this cases the seat, are mounted

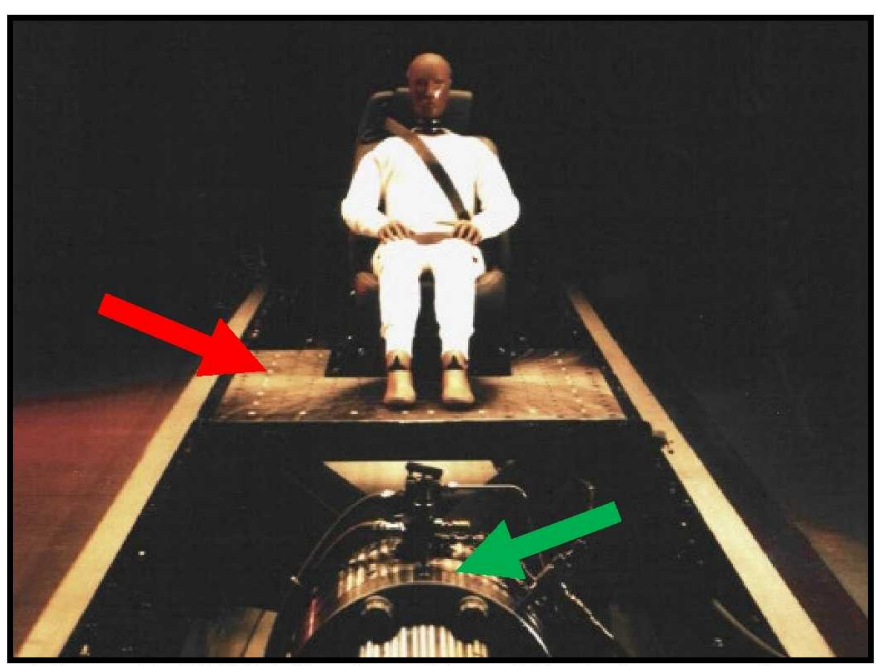

Figure 5: HYGE Carriage Noted Red; Actuator Green

To meet all these requirements, a large steel frame-like seat fixture was designed as shown in Figure 6. Features include:
A: Carriage interface block
B: Seat adjustment linkages
C: Seat Pan
D: Seat Back and Headrest
E: Leg Pan
F: Lateral Knee, Hip, Shoulder Bolsters; Z-axis Shoulder Bolsters (all removable)
G: Five-Point Harness Attachment Points 
Also shown but not labeled are the attachment points for the 5-point harness. One can be seen directly behind the headrest. Note that this seat, although shown in its vertical orientation (for $\mathrm{a}+\mathrm{X}$ or $-\mathrm{X}$ test) can also be rotated 90 degrees clockwise from shown position for a $Z$ test or 90 degrees out of plane for a $Y$ test. The carriage interface block was designed to provide the means to fix itself to the carriage regardless of orientation.

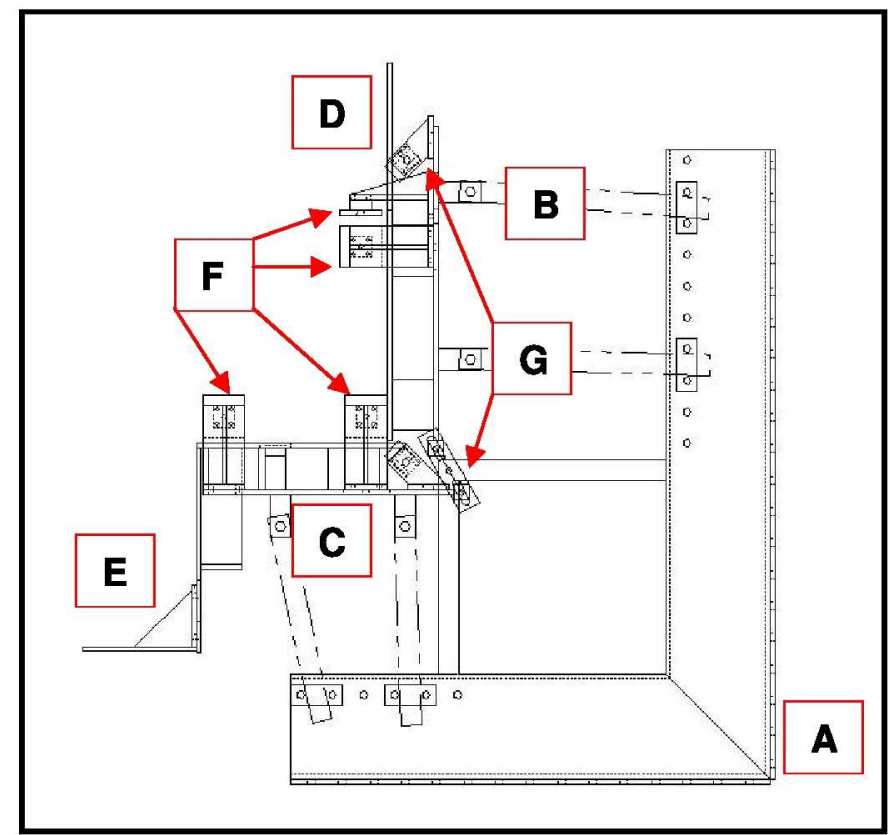

Figure 6: OSU/TRC Sled Testing Seat Design

Although there were some minor design changes along the way, mostly for additional anthropometric range and bracing to minimize vibration, the final constructed seat looks extremely similar to the original specified design. The final seat is shown below in Figure 7. Relevant features are also marked, with the exception of the removable lateral supports $(F)$ which are not shown.

The CSSE team worked closely with the Orion seat team to ensure that this seat provides representative restraint and lateral support. This seat design employs a 90 degree seat back to seat pan angle, which is not representative of the Orion design; however, after discussion with the Orion seat team it was felt that this 90 degree design would have a negligible impact on data fidelity for the tests performed, and a 90 degree angle was highly desired due to simplicity of design.

In addition, this seat is capable of accommodating a large quantity of instrumentation which will be discussed later in this paper.

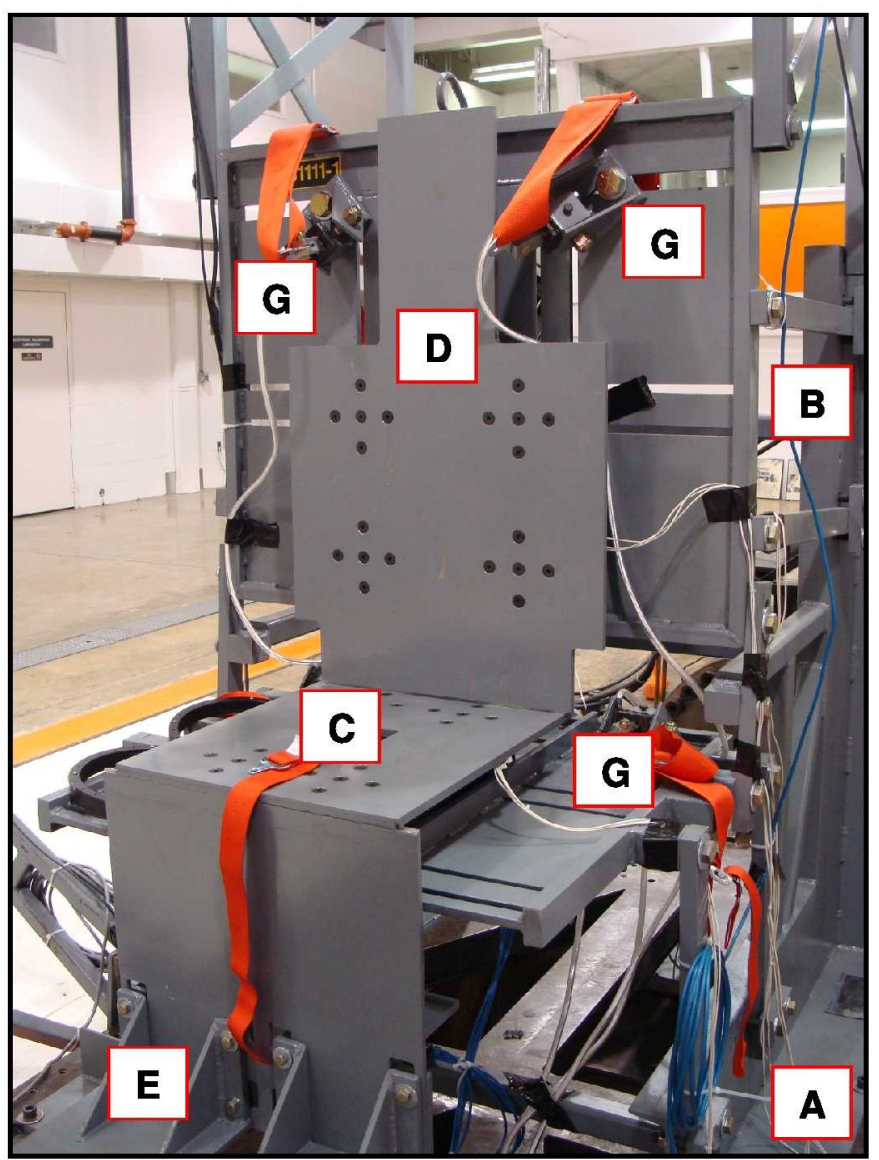

Figure 7: Final Seat Design

\section{SUIT SIMULATOR}

In order to test the primary objective of qualifying injury risk associated with rigid suit components, specific hardware was required to simulate these rigid components without employing the use of an authentic and complete spacesuit, which would be costly and timeconsuming. Therefore, a suit simulator was designed at JSC to provide an analog of these specific rigid architectural features but also provide quick don and doff capability, repeatability and ease of use. The design concept for this "Suit Simulator" is shown below in Figure 8.

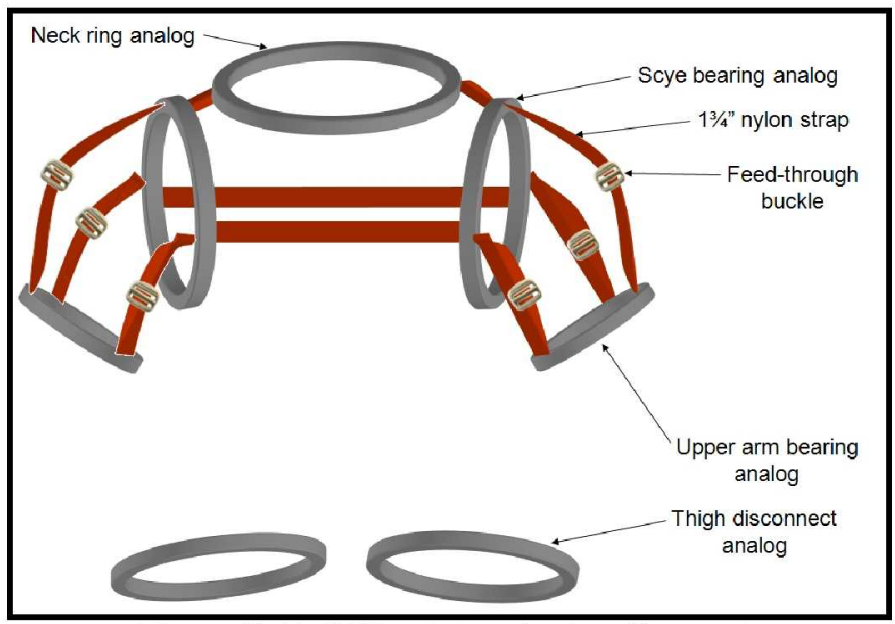

Figure 8: Suit Simulator Design Concept 
As shown, the Suit Simulator provides the architectural features of the suit relevant to this test in the scye and upper arm bearings, the neck ring, and thigh disconnect. In the final design, the front of and rear straps employed the use of Velcro to provide adjustability of inter-scye spacing and ease of use. The initial construction of the suit simulator is shown in its fit check below in Figure 9.

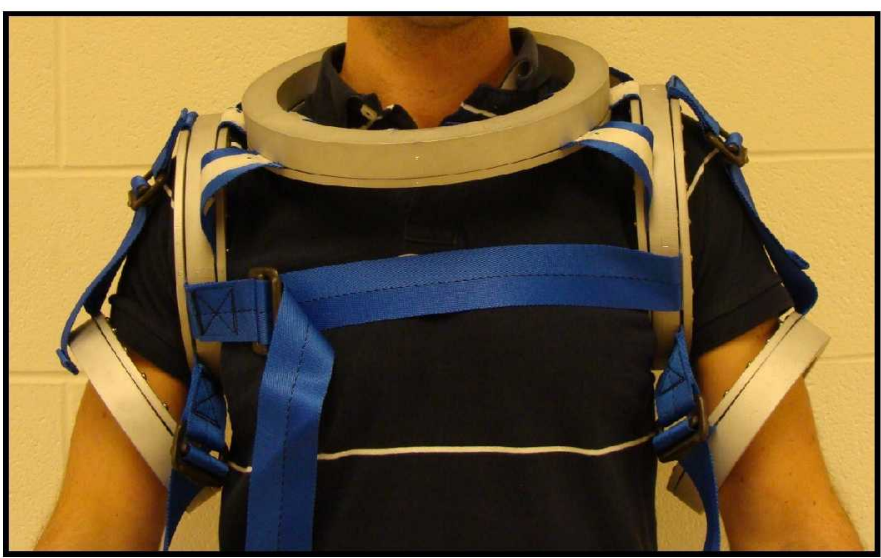

Figure 9: Initial Suit Simulator Design Fit Check

\section{HARNESSES}

A commercial off-the-shelf five-point harness was selected for this testing due to its similarity to the current reference restraint design, which is a 5-point harness with 3" straps. The specific product selected was the GForce 5-point Cam-Lock Pull-Down harness, shown below in Figure 10 . Each harness is being replaced every three test points to ensure that any material fatigue due to cyclic loading does not affect the results.

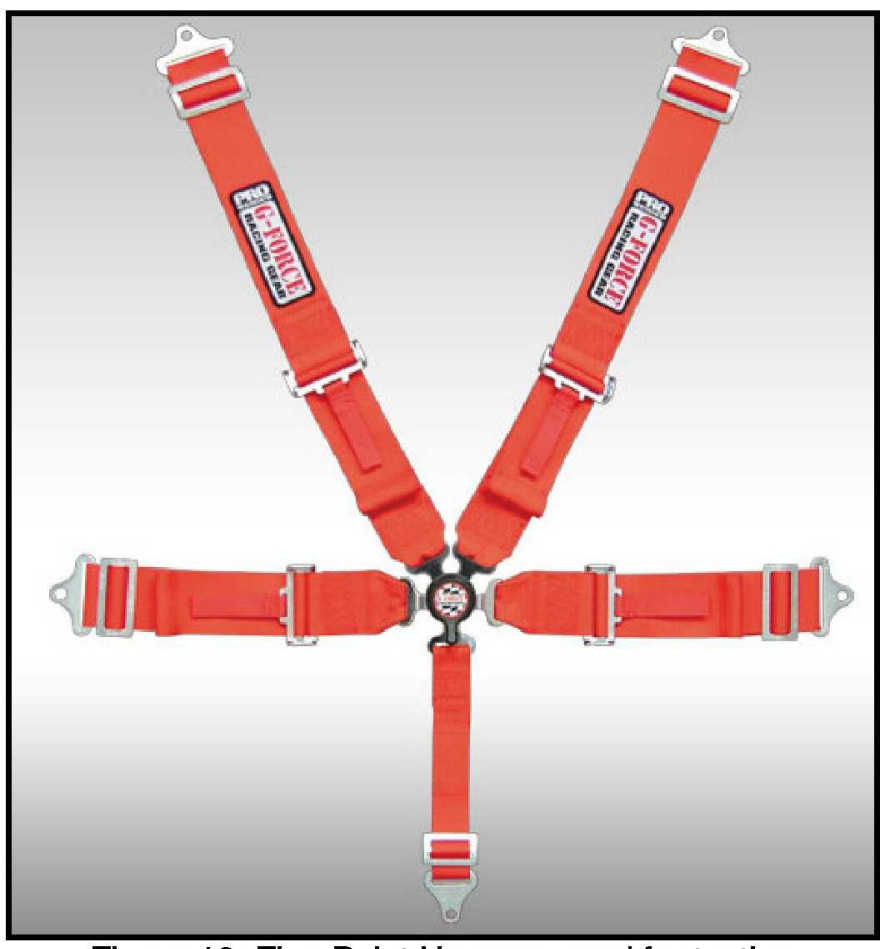

Figure 10: Five-Point Harness used for testing

\section{DATA RECORDING}

A very large amount of data is being recorded for this test to ensure everything worth capturing is documented.

As for imagery, depending on the test direction we have as many as three on-board video cameras and two offboard video cameras to capture the event. These high resolution $(1000 \times 1000)$, high speed (1000 frames per second) cameras are positioned for each specific test direction to best capture the landing event, the test subject, the restraints, and the relevant seat architectural features the subject interacts with. The testing facility accommodates these video cameras in nearly any position around the subject, including oblique and overhead angles.

In addition, images and video of the seat, subject, harness and suit simulator positioning, etc. are taken directly before and after each test run. This provides valuable data that may not be captured in the video taken during the landing event itself, which is only recorded for approximately 250 milliseconds.

On the seat, an array of accelerometers and load cells are mounted in relevant locations to provide feedback on the specifics of the landing event. Details are below in Table 2.

\begin{tabular}{|c|c|}
\hline Seat Location & Measuring Technique \\
\hline $\begin{array}{l}\text { HYGE Carriage } \\
\text { (Front) }\end{array}$ & Triaxial Accelerometer \\
\hline $\begin{array}{l}\text { HYGE Carriage } \\
\text { (Rear) }\end{array}$ & Triaxial Accelerometer \\
\hline Seat Back & $\begin{array}{l}\text { Triaxial Accelerometer } \\
\text { (4) Triaxial Load Cells }\end{array}$ \\
\hline Seat Pan & $\begin{array}{l}\text { Triaxial Accelerometer } \\
\text { (4) Triaxial Load Cells }\end{array}$ \\
\hline Seat Frame & Triaxial Accelerometer \\
\hline Harnesses & $\begin{array}{l}\text { Triaxial Load Cell at each } \\
\text { Harness Attachment Point }\end{array}$ \\
\hline Lateral Support & $\begin{array}{l}\text { Triaxial Load Cell at each } \\
\text { (Knee, Hip, Shoulder) }\end{array}$ \\
\hline Z-Axis Support & $\begin{array}{l}\text { Triaxial Load Cell at each } \\
\text { (Shoulder) }\end{array}$ \\
\hline
\end{tabular}

Table 2: Seat Instrumentation

Although the seat has the same instrumentation for every test run (with the exception of the lateral support load cells, where the lateral supports are removed for test in which they are not required), the PMHS will often get instrumented for a specific test direction or directions. However, much of the instrumentation is the same for each subject. For example, every subject gets instrumented with the same strain gauge array (strain gauges mounted directly on the bone provide a time of 
fracture in the event one is found) and multiple triaxial accelerometer/angular rate sensors [ARS]. The table below shows the full set of PMHS data acquisition being used for this test; italicized text indicates this measurement is not used on every data point, and is dependent on testing direction.

\begin{tabular}{|l|l|}
\hline PMHS Location & Measuring Technique \\
\hline $\begin{array}{l}\text { Medial \& Lateral } \\
\text { Aspects of Right \& } \\
\text { Left Clavicles }\end{array}$ & Strain Gauges \\
\hline $\begin{array}{l}\text { Proximal \& Distal } \\
\text { Aspects of Right \& } \\
\text { Left Humeri }\end{array}$ & Strain Gauges \\
\hline $\begin{array}{l}\text { Acromion Process } \\
\text { of Right \& Left } \\
\text { Scapula }\end{array}$ & Strain Gauges \\
\hline $\begin{array}{l}\text { Manubrium \& } \\
\text { Body of the } \\
\text { Sternum }\end{array}$ & Strain Gauges \\
\hline $\begin{array}{l}\text { Ribs 3-8 Both } \\
\text { Right \& Left Sides }\end{array}$ & Strain Gauges \\
\hline Sternum & Triaxial Accelerometer/ARS \\
\hline T-4 Vertebra & Triaxial Accelerometer/ARS \\
\hline T-8 Vertebra & Triaxial Accelerometer/ARS \\
\hline T-12 Vertebra & Triaxial Accelerometer/ARS \\
\hline S-1 Vertebra & Triaxial Accelerometer/ARS \\
\hline
\end{tabular}

Table 3: PMHS Instrumentation

An example figure demonstrating the location of these sensors on the PMHS is shown below in Figure 11.

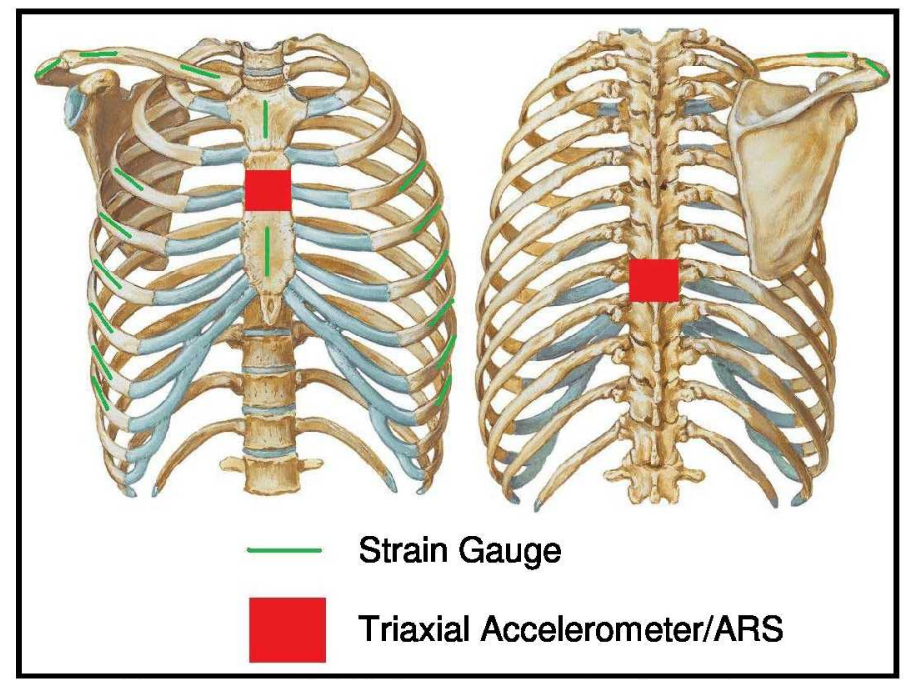

Figure 11: PMHS Instrumentation Locations

All data is collected at a sample rate of $1000 \mathrm{~Hz}$ and filtered according to SAE J211 standards; however, both filtered and unfiltered data are recorded.

\section{TEST PROCEDURE}

Due to subject procurement and logistical restraints, it is only possible to test two or three subjects during a given test week. Several days prior to testing, the PMHS are removed from the freezer, if necessary, for thawing and instrumentation. Also at this stage, the pre-test radiology of the relevant anatomical areas is performed in the way of X-Rays, MRI or CT depending on test direction. All of this occurs at The Ohio State University IBRL, and when complete, the test subject is transported to TRC for acceleration testing.

Once at the testing facility, the subject is outfitted with the suit simulator and connected to the data acquisition system off the seat, while final system preparations are completed (positioning, camera adjustments, bolster and harness reconfiguration, etc).

Before every collected test point, two test trial runs are completed. The first is a trial run with an empty seat. This "inertial pulse" provides the seat system a means to exhibit any anomalous behavior due to the recent reconfiguration, and also provides a baseline against which to calibrate the load cells and accelerometers. Lastly it allows us to view the output from the data acquisition system to look for any problems.

In the second trial run, called a "shakedown pulse", an $50^{\text {th }}$ percentile male Hybrid III ATD is placed into the seat and restrained with the harnesses. This trial run provides extra assurance against missing something that could have a negative impact on the PMHS test run. Secondly, the data from this trial run is also more analogous to the PMHS test, as the subject/seat impact can be observed and measured. Some of these images taken prior to $\mathrm{a}+\mathrm{Z},-\mathrm{Z}$ and $+\mathrm{Y}$ tests are shown below in Figures 12,13 and 14 respectively.

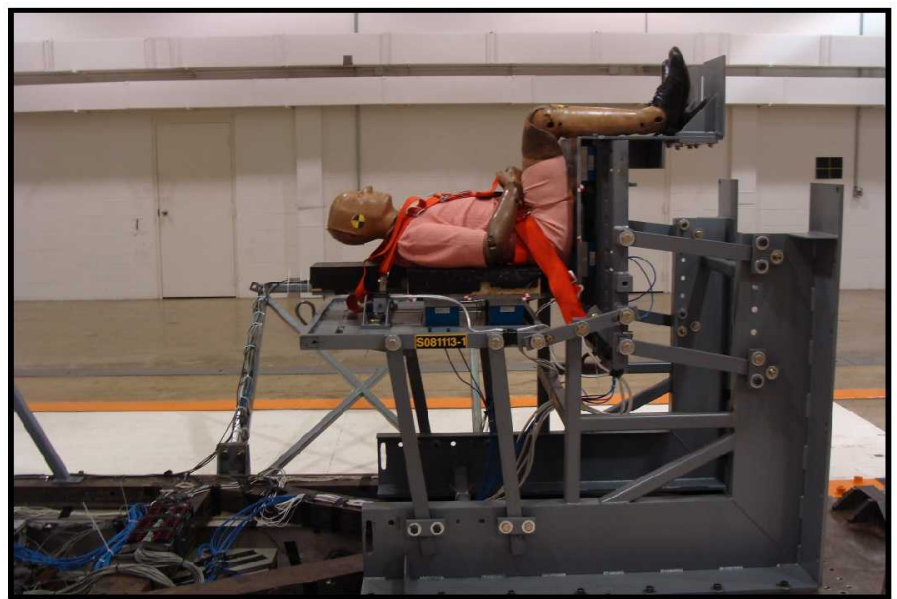

Figure 12: ATD Trial (+Z Configuration) 


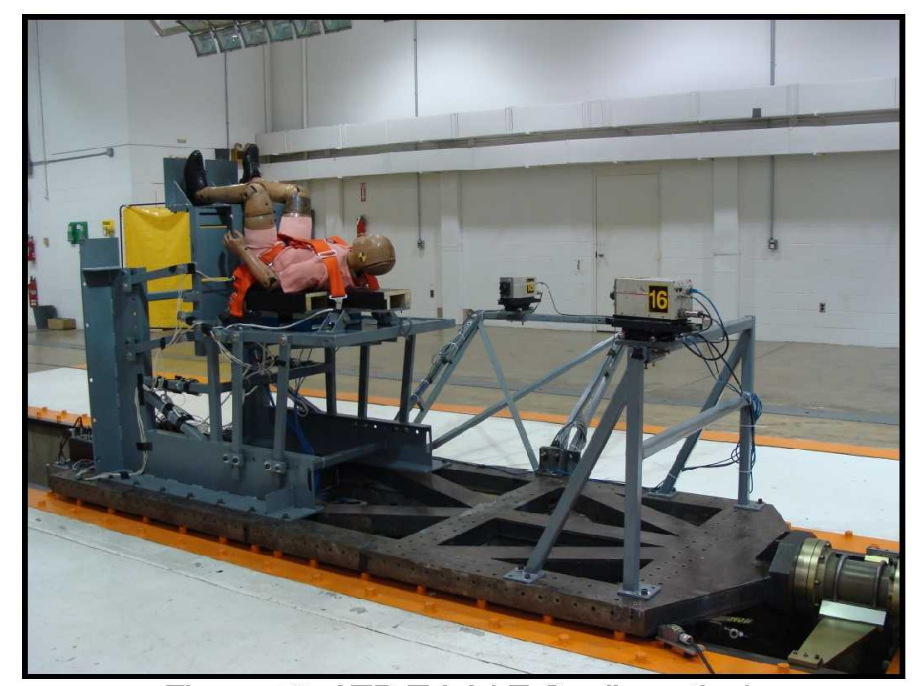

Figure 13: ATD Trial (-Z Configuration)

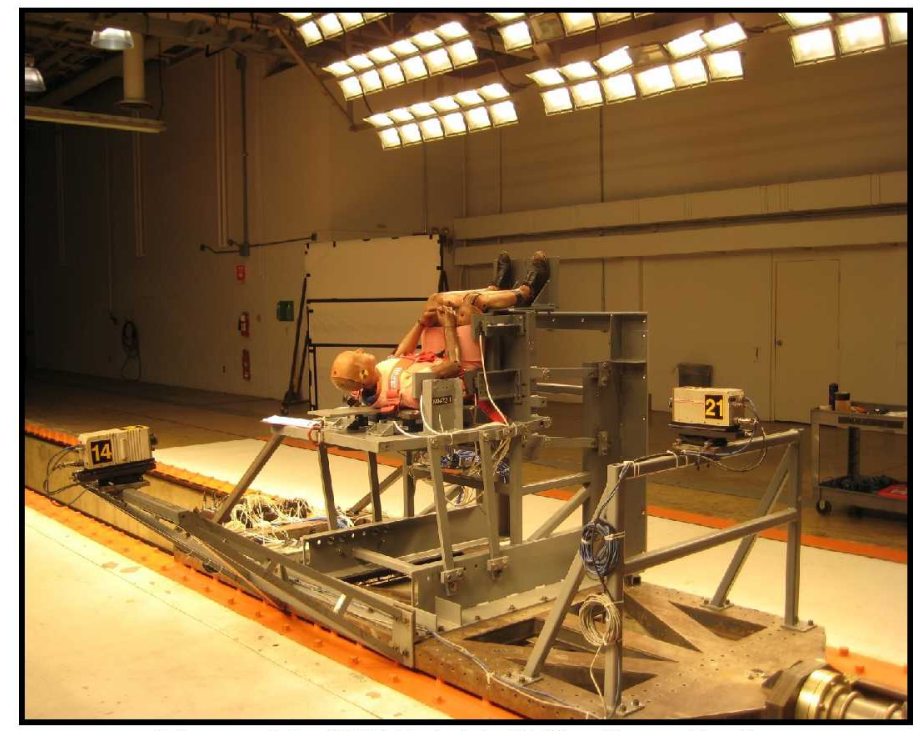

Figure 14: ATD Trial (+Y Configuration)

Once these trial runs are completed, the PMHS is inserted into the seat and restrained with the harnesses. Great care is taken to ensure consistent and representative positioning of the subject in the seat, the suit simulator on the subject, and the restraint harness. A soft cervical collar was used to keep the head of the subject in a semi-typical position, when necessary. The shoulder harnesses are placed directly over the scye bearings and all harnesses are tightened to $20+/-3$ pounds of tension as measured by the load cells at each harness attachment point.

Once this is complete, pre-test imagery is taken, and FARO measurements are taken on the subject and the seat to define the subject's coordinate system and initial positioning on the seat. Final checks are then performed, and the test is executed. The complete test setup, as demonstrated by a live human test conductor during a hardware fit check, is shown below in Figure 15, and a detail is shown in Figure 16.

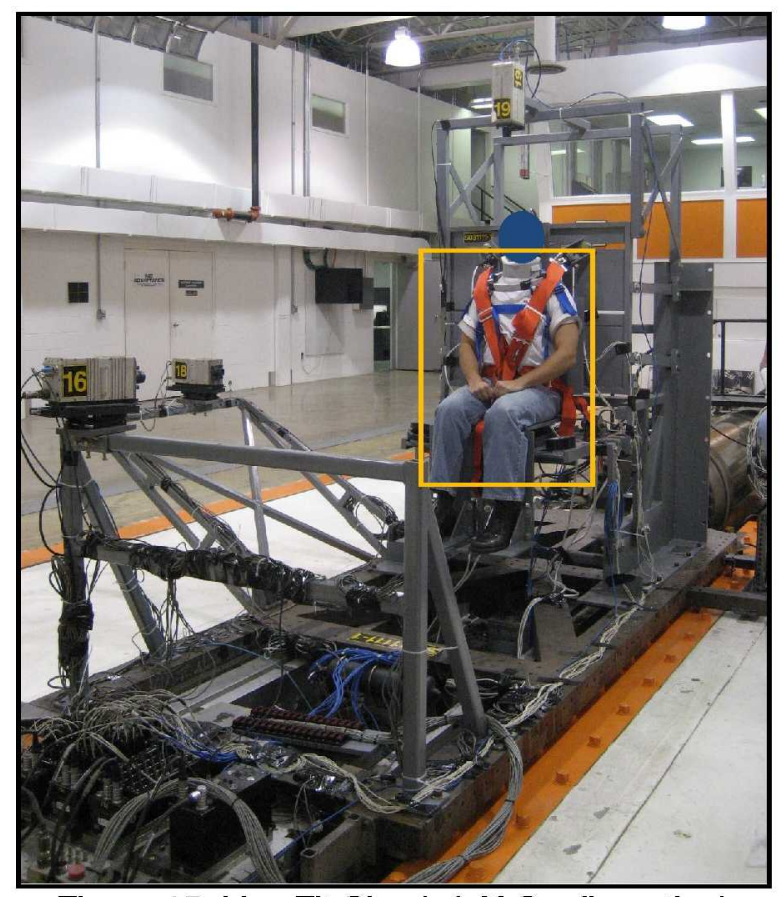

Figure 15: Live Fit Check (+X Configuration)

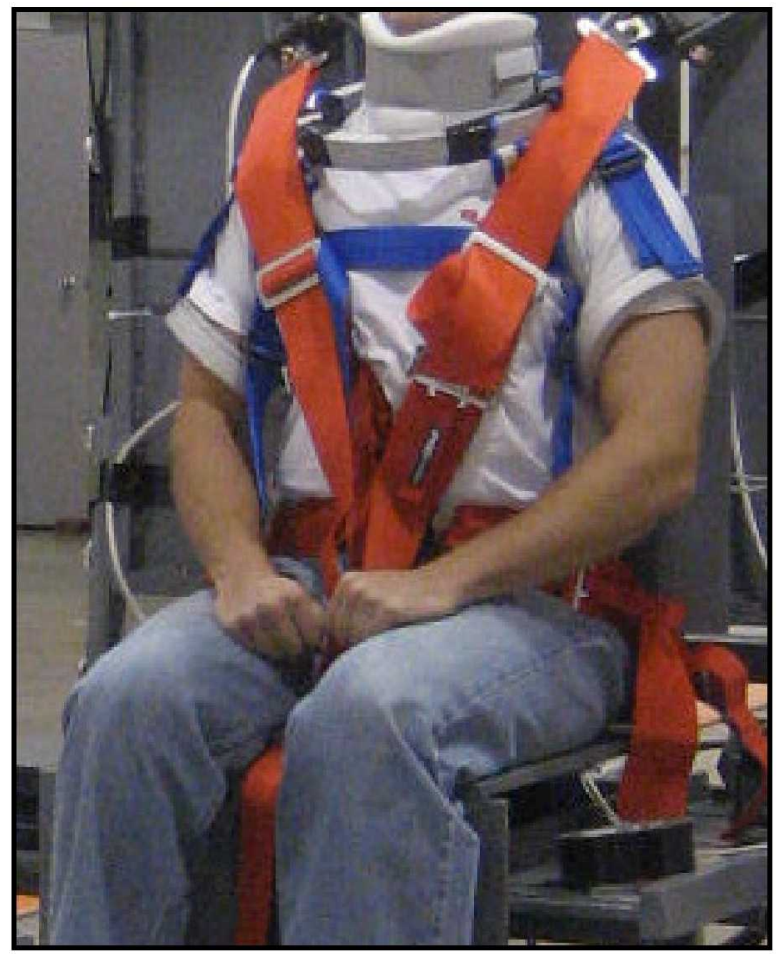

Figure 16: Detail from Live Fit Check

Immediately after the acceleration event, post-test imagery is taken of the seat and PMHS for later comparison against the pre-test images. The subject is removed from the seat and transported back to the IBRL for post-test radiology. By performing both pre and post test imaging, it is possible to see injuries before autopsy, as well as confirm that these injuries did not occur before the test.

The last and most important step in the testing process is post-test autopsy. These are conducted by the IBRL 
at The Ohio State University, often in conjunction with support from NASA Medical Operations and Flight Doctors, who can provide insight into potential injuries as they relate to human spaceflight and the Constellation Program architecture. For example, while an injury may have minimal impact to the inherent health or safety of a person in a car crash, it may have a much worse consequence for a crewmember that needs to be able to self-egress from the vehicle in an emergency scenario.

\section{ANALYSIS AND PRELIMINARY RESULTS}

Not only are the measuring devices in Tables 2 and 3 useful in providing direct data like body acceleration, body rotation, time of fracture, harness loads, seat bolster loads, loads into the seat, and accelerations of the various seat components and of the HYGE carriage, these measurements can also provide indirect data through integration or correlation with other measuring devices. For example, all accelerometers provide velocity and displacement data with respect to time so the movement of the subject can be quantified. Comparing two displacement curves to each other allows calculation of chest or spinal compression, each important metrics in evaluating injury potential.

Lastly, in the event of two contradictory tests, it may be possible to compare the harness, seat back, seat pan, or seat bolsters across the two tests to locate any anomalies that may lead to a specific cause of injury or further recommendation for corrective action.

As of January 2010, six of the twelve subjects have been tested as shown highlighted in Table 4. However, the full details of the results will not be released until 2011 (pending test series completion). It is important to reserve discussion until that time such that data points are not discussed individually or in the raw, but in the context of a completed and analyzed test program.

\section{CONCLUSION}

In support of the Constellation Program Space Suit Element, a new space-suit architecture will be created for support of LEA, microgravity EVA, and nominal and off-nominal post landing crew operations. The CSSE architecture is unique in comparison to previous programs in that it employs the use of rigid mobility elements in the shoulder and the upper arm regions, as well as thigh disconnect elements to provide a quick disconnect feature above the knee for commonality between different suit configurations. Risks have been identified with potential injury due to these specific suit architectural features and their interface with the Orion vehicle seat during dynamic phases of flight, especially during landing.

To address these risks, a test series is underway in coordination with the IBRL at The Ohio State University to evaluate the likelihood and consequences of these potential injuries. This testing includes use of Post
Mortem Human Subjects and representative seat/suit hardware in high acceleration events, which provide an analog for a true Orion landing event.

Preparation for this test series entailed developing this new seat and suit analog hardware, as well as a detailed and comprehensive instrumentation system capable of providing direct measurements not only of the seat, but of the PMHS itself.

\begin{tabular}{|c|c|c|c|}
\hline $\begin{array}{l}\text { Test } \\
\text { Point }\end{array}$ & Subject & Direction & Area of Focus \\
\hline 1 & A & $+X$ & Posterior Shoulder \\
\hline 2 & B & $-X$ & Anterior Shoulder \\
\hline 3 & \multirow{2}{*}{ C } & $-\mathbf{Z}$ & Superior Shoulder \\
\hline 4 & & $+Z$ & Thigh and Backbone \\
\hline 5 & $\mathrm{D}$ & $+\mathrm{X}$ & Posterior Shoulder \\
\hline 6 & $E$ & $-X$ & Anterior Shoulder \\
\hline 7 & \multirow{2}{*}{$F$} & $+Y$ & Rib, Shoulder, etc. \\
\hline 8 & & $-Y$ & Rib, Shoulder, etc. \\
\hline 9 & \multirow{2}{*}{$\mathrm{G}$} & $-\mathbf{Z}$ & Superior Shoulder \\
\hline 10 & & $+\mathbf{Z}$ & Thigh and Backbone \\
\hline 11 & \multirow{2}{*}{$\mathrm{H}$} & $+\mathrm{X}$ & Posterior Shoulder \\
\hline 12 & & $+Z$ & VIE \\
\hline 13 & \multirow{2}{*}{1} & $-X$ & Anterior Shoulder \\
\hline 14 & & $+\mathrm{X}$ & VIE \\
\hline 15 & \multirow{2}{*}{$J$} & $-\mathbf{Z}$ & Superior Shoulder \\
\hline 16 & & $+Z$ & Thigh and Backbone \\
\hline 17 & \multirow{2}{*}{$\mathrm{K}$} & $+Y$ & Rib, Shoulder, etc. \\
\hline 18 & & $+\mathrm{X}$ & VIE \\
\hline 19 & \multirow{2}{*}{$\mathrm{L}$} & $+Z$ & VIE \\
\hline 20 & & $+\mathrm{X}$ & VIE \\
\hline
\end{tabular}

Table 4: Test Matrix Status

Of the scheduled 20 test points across 12 PMHS, ten test points and six subjects have been completed as of January 2010. Full detailed results and analysis of all data points will be released in 2011, pending test program completion. 


\section{REFERENCES}

(1) "CSD-A-017, Apollo Space Suit Assembly Design and Performance Specification, Final Review Copy". Manned Spaceflight Center, Houston: NASA. 12-Oct1964.

(2) "CPS-65-13, NASA Developmental Study of the Apollo Helmet Assembly". Manned Spaceflight Center, Houston: NASA. 16-Jul-1965.

(3) "HES-67-16, "Apollo Helmet-Suit Interface Study". Manned Spaceflight Center, Houston: NASA. 13-Jul1967.

(4) "CxP 72208, Constellation Space Suit Element Requirements Document." Draft. JSC, Houston: NASA, 05-Jun-2008.

\section{CONTACT}

Mark O. Dub currently works at NASA Johnson Space Center as the Constellation Space Suit Element Configuration 1 Lead. A graduate of the University of Michigan, he has worked at Johnson Space Center since XXX. He can be reached at mark.o.dub@nasa.gov.

Shane M. McFarland currently works at NASA Johnson Space Center as a Senior Project Engineer on the Constellation Space Suit Pressure Garment Subsystem. His education is in Physics, Mechanical Engineering, Aerospace Engineering and Bioastronautics. He can be reached at shane.m.mcfarland@nasa.gov.
DEFINITIONS, ACRONYMS, ABBREVIATIONS

ACES: Advanced Crew Escape Suit

ARS: Angular Rate Sensor

ATD: Anthropomorphic Test Device

CSSE: Constellation Space Suit Element

CT: Computer Tomography

EMU: EVA Mobility Unit

ESR: EVA System Reference

EVA: Extra-Vehicular Activity

IBRL: Injury Biomechanics Research Laboratory

JSC: Johnson Space Center

LEA: Launch, Entry, Abort

MRI: Magnetic Resonance Imaging

OSU: The Ohio State University

PMHS: Post-Mortem Human Subjects

SAE: Society of Automotive Engineers

TRC: Transportation Research Center

VIE: Vehicle Interface Element 
